\title{
Pregnancy and Chagas Disease: Benznidazole's Impact on Pregnancy and Newborns: A Report of Four Cases
}

\author{
Cristina Vázquez, ${ }^{1 *}$ Elisa García-Vázquez, ${ }^{1,2}$ Bartolomé Carrilero, ${ }^{1}$ Marina Simón, ${ }^{1}$ Fuensanta Franco, ${ }^{1}$ Maria A. Iborra,,${ }^{1,2}$ \\ Luis J. Gil-Gallardo, ${ }^{1}$ and Manuel Segovia ${ }^{1,2}$ \\ ${ }^{1}$ Unidad de Medicina Tropical, Hospital Clínico Universitario Virgen de la Arrixaca, Murcia, Spain; ${ }^{2}$ Universidad de Murcia, Murcia, Spain
}

\begin{abstract}
In recent decades and because of migration, Chagas disease has become a global public health problem. A significant focus has been placed on pregnant women who can transmit the disease to their offspring. Here, we report four cases of women who did not know that they were pregnant while they were being treated with benznidazole. A diagnosis was established according to serology and Trypanosoma cruzi polymerase chain reaction (PCR)-standardized tests. Treatment was discontinued when pregnancy was confirmed, and a thorough follow-up was carried out. Although each case was different, none of the mothers developed health problems during pregnancy, and their newborns were delivered without any teratogenic effects.
\end{abstract}

\section{INTRODUCTION}

American trypanosomiasis is a vector-borne infection caused by the protozoan parasite Trypanosoma cruzi, ${ }^{1}$ although it may also be transmitted through blood transfusions or from mother to child during pregnancy. ${ }^{2}$ There are two drugs currently available for its treatment, nifurtimox and benznidazole, launched in 1967 and 1973, respectively, which have been shown to be effective for treatment during the acute phase of the infection. Previously, there was no international consensus regarding the treatment of the chronic phase because of the high frequency of undesirable side effects and poor indications of an apparent cure. ${ }^{3}$ Despite this, in recent decades, drug treatment has been offered and benznidazole is considered the first-line therapy. ${ }^{4,5}$ The treatment of infected women of childbearing age prevents congenital infection, ${ }^{6}$ but the side effects of benznidazole discourage its use in pregnant women. ${ }^{7}$ However, no side effects have been reported during breastfeeding. ${ }^{8,9}$ For ethical reasons, there have been no high-quality studies regarding treatment in pregnant women (benznidazole was found to cross the placental barrier and bind to fetal proteins in experimental rat models in the early 1980s), ${ }^{10}$ and a strong recommendation not to treat during pregnancy is given in different guidelines. ${ }^{7,11,12}$ Therefore, guidance regarding effective contraception during benznidazole treatment should be given to women of reproductive age. A few cases of uneventful benznidazole treatment of acute Chagas disease during pregnancy have been reported. ${ }^{13-16}$ Our aim was to present four cases (part of our larger Chagas patients' cohort) of pregnant women (and their newborns) who were treated with benznidazole while they were unaware of their pregnancy.

\section{PATIENTS AND METHODS}

Patients were diagnosed with Chagas disease through two complementary methods: a chemiluminescent microparticle immunoassay (ARCHITECT Chagas ${ }^{\circledR}$, Abbott, Chicago, IL) and an indirect immunofluorescent assay (Inmunofluor

\footnotetext{
*Address correspondence to Cristina Vázquez, Unidad de Medicina Tropical. Hospital Clínico Universitario Virgen de la Arrixaca, Ctra. MadridCartagena, s/n, 30120 El Palmar, Murcia, Spain. E-mail: cristinavzq@ gmail.com
}

Chagas kit, Biocientifica S.A., Buenos Aires, Argentina). In addition, PCR was performed, as previously described, to search for the parasite in the peripheral blood. ${ }^{17}$

During the study period (2007-2017), more than 1,500 patients received benznidazole in our Tropical Medicine Outpatient Clinic. Four cases of women who did not know that they were pregnant when treated with benznidazole were analyzed according to our standard protocol. ${ }^{17}$

Patients were treated orally with benznidazole $(100 \mathrm{mg})$ three times a day for 60 days. ${ }^{18}$ The cumulative dose did not exceed $18 \mathrm{~g}$ of benznidazole to prevent some of the known side effects, such as polyneuritis and bone marrow depression, as stated in previous reports. ${ }^{19}$ Side effects of benznidazole were considered to be present when women described any abnormal pregnancy symptoms or signs of common benznidazole side effects, including abdominal pain, rash, weight loss, headache, nausea, vomiting, low white blood cell count (neutropenia and eosinophilia), hives, itching, decreased appetite, hypersensitivity skin reactions, and diarrhea. Other events during pregnancy, such as anomalous findings by echography, high blood pressure, or unexpected hemogram parameters were also registered.

As part of our standard of care, before benznidazole administration, all patients were given advice regarding treatment, including information about Chagas disease, benznidazole doses, and possible side effects. They were also advised not to drink alcohol and not to eat spicy or fatty food, and in the case of childbearing age women, information to prevent pregnancy was provided. Women who were found to be pregnant during treatment were advised to stop medication, and information about the discontinuation of pregnancy was given.

\section{RESULTS}

Of the 1,580 treated patients, women represented more than half of the cohort $(62.8 \%): 84.9 \%$ were of childbearing age (15-50 years) and 176 got pregnant during the study period, nearly all after finishing the treatment or without starting it. Nevertheless, four cases of unexpected pregnancy during benznidazole treatment were registered. All patients were from Bolivia (in our cohort, $93.9 \%$ of the women were from this country). The main characteristics of these women and their newborns are described in Tables 1 and 2. 
TABLE 1

Characteristics of pregnant women

\begin{tabular}{|c|c|c|c|c|c|c|c|c|c|c|c|}
\hline Mother & Country & $\begin{array}{c}\text { Age } \\
\text { (years) }\end{array}$ & $\begin{array}{l}\text { Years in } \\
\text { Spain }\end{array}$ & Kuschnir $^{\star}$ & Serology & $\begin{array}{l}\text { Pretreatment } \\
\text { PCR }\end{array}$ & Posttreatment PCR & $\begin{array}{l}\text { Days of } \\
\text { treatment }\end{array}$ & $\begin{array}{c}\text { Pregnancy at } \\
\text { discontinuation (weeks) }\end{array}$ & $\begin{array}{l}\text { Treatment of } \\
\text { adverse events }\end{array}$ & $\begin{array}{l}\text { Incidents during } \\
\text { pregnancy }\end{array}$ \\
\hline 1 & Bolivia & 27 & 6 & I & Positive & Positive & Positive & 20 & 5 & No & No \\
\hline 2 & Bolivia & 38 & 5 & I & Positive & Positive & Negative & 30 & 10 & No & No \\
\hline 3 & Bolivia & 15 & 10 & I & Positive & Negative & Negative & 60 & $4-6$ & No & No \\
\hline 4 & Bolivia & 31 & 4 & 0 & Positive & Not performed & Negative & 15 & 6 & No & No \\
\hline
\end{tabular}

Case 1 was a 27-year-old woman who had been living in Spain for 6 years. Asymptomatic Chagas disease was diagnosed (Kuschnir I and normal digestive study). The Chagas PCR was positive before treatment initiation; 20 days after being on benznidazole, she decided to discontinue treatment because of a positive pregnancy test. She was in her fifth gestational week. During pregnancy, no adverse events were reported. A second PCR test just before birth remained positive. Her child was born at full term, with no complications during spontaneous vaginal delivery, and no malformations or teratogenicity were found (weighed, $3.4 \mathrm{~kg}$ ); however, $T$. cruzi PCR was positive, and both the mother and the newborn received a 60-day course of benznidazole. After that, the family returned to Bolivia, and there was no follow-up.

Case 2 was a 38-year-old Bolivian woman who had been living in Spain for 5 years diagnosis of asymptomatic Chagas disease was given because of a positive PCR test. After being on benznidazole treatment for 1 month, trypanocidal treatment was discontinued because of a 10-week pregnancy. After that, no adverse events were reported. A second PCR test just before delivery was negative. Her child was Caesarean-born at full term with no complications. The newborn was healthy, with no signs of teratogenicity. Although the serology test was positive in the first days of life, it became negative during the first year, and the $T$. cruzi PCR test was also negative. In the 6 years of follow-up, the child did not develop any relevant health problems.

Case 3 was a 15-year-old Bolivian female who had been living in Spain for 10 years. Chagas PCR was negative, and at the end of a 60-day course of benznidazole treatment, she discovered she was pregnant (fourth or sixth week of gestation). During her pregnancy, no adverse events were reported. Her child was born with no complications (vaginal delivery; weight, $3.4 \mathrm{~kg}$ ). Neither genetic malformations nor teratogenicity was found. The serology test was positive in the first days of life, but became negative by the end of the first year of life. The Chagas PCR test was also negative at birth. In the three years of follow-up, no medical problems have been reported.

Case 4 was a 31-year-old Bolivian woman who had been living in Spain for 4 years. Chagas PCR was not performed, and the treatment was prescribed according to a positive serology test. After 15 days, benznidazole was discontinued as she discovered that she was pregnant (fifth week). She decided to continue her pregnancy, and no adverse events were reported. A negative T. cruzi PCR was reported before delivery. Her child was born at full term without complications by vaginal delivery. The newborn was healthy, and the Chagas serology test was negative during the first year of life. The T. cruzi PCR was negative. In the 3-year follow-up period, the child did not develop any relevant health problems.

\section{DISCUSSION}

Approximately $1-10 \%$ of the infants born from infected mothers develop acute T. cruzi infection. ${ }^{21}$ It has been demonstrated that women who complete a course of benznidazole treatment before getting pregnant are able to prevent congenital infection. ${ }^{6}$ For this reason, treatment should begin as soon as infection is detected in women of childbearing age. At the same time, this drug should not be administered during pregnancy. Despite the recommendation to use contraception, some women may get pregnant during treatment, may realize this weeks after taking benznidazole, and may not want to discontinue their pregnancy.

Our four cases are unique. Each mother's disease course was different, illustrating four possible scenarios concerning pregnancy and simultaneous Chagas disease treatment.

In our cohort, two women (cases 1 and 2) tested positive for $T$. cruzi PCR before pregnancy. In case 1 , having received only 20 days of treatment, the woman remained positive after delivery, and she transmitted the infection to her newborn. On the other hand, in case 2, the woman fulfilled a 30-day course of treatment, and her PCR was negative by the time of delivery; she did not transmit the infection to her offspring. These data make us consider the minimum duration of treatment necessary for a negative PCR test, therefore avoiding the risk of congenital transmission. Although some authors have focused on this topic, further studies are needed to provide clarification. $^{22-26}$

In our cohort, benznidazole was administered in the first trimester in three patients and during the second trimester in another case, having completed between 15 and 60 days of benznidazole treatment. However, benznidazole may be carcinogenic, teratogenic, and cause reproductive toxicity and/or genotoxicity. To investigate its teratogenicity in animal

TABLE 2

Characteristics of newborns

\begin{tabular}{|c|c|c|c|c|c|c|c|}
\hline Children & Delivery & Prematurity & Teratogenicity & $\begin{array}{c}\text { Congenital Chagas } \\
\text { disease }\end{array}$ & PCR & Treatment & Follow-up (years) \\
\hline 1 & Vaginal delivery & No & No & Yes & Positive & Yes & 1 \\
\hline 2 & Caesarian & No & No & No & Negative & No & 6 \\
\hline 3 & Vaginal delivery & No & No & No & Negative & No & 3 \\
\hline 4 & Vaginal delivery & No & No & No & Negative & No & 3 \\
\hline
\end{tabular}


models, a single study has been performed since the approval of benznidazole. The results describe transplacental trespassing and covalent binding of its metabolites to fetus proteins. ${ }^{10}$ Although the analysis of teratogenicity was not the aim of this study, the potential risk of benznidazole could not be excluded. Some studies that have focused on nitroimidazoles (benznidazole's same structural family) report different data, either establishing the safety of the compounds or determining that members of this family may cause teratogenic effects in humans and mice during different stages of pregnancy. ${ }^{26-29}$

In our series, in addition to the small sample size, the short treatment course undermines the reliability of definite conclusions about the effects of benznidazole on mothers and newborns. Previous reports describe cases in which the decision to treat was made based on the risk to the mother and/or fetus and concluded a positive risk/benefit balance. ${ }^{13-16}$

With the current knowledge, we cannot propose treating pregnant women, but it is important to report any further experience with pregnancy and benznidazole that may provide additional information on this topic.

Received May 6, 2019. Accepted for publication January 20, 2020.

Published online March 23, 2020.

Acknowledgments: We would like to thank the gynecologists of Hospital Clínico Universitario Virgen de la Arrixaca for their collaboration with our unit.

Financial support: This study was supported by the RICET Tropical Disease Research Network (RD16/0027/0016) from the Instituto de Salud Carlos III (ISCIII) and FEDER.

Authors' addresses: Cristina Vázquez, Bartolomé Carrilero, Marina Simón, Fuensanta Franco, and Luis J. Gil-Gallardo, Hospital Universitario Virgen de la Arrixaca, Murcia, Spain, E-mails: cristinavzq@ gmail.com, bartolome.carrilero@carm.es, marinasimon899@gmail.com, fuensanta.franco@carm.es, and luisgilga@gmail.com. Elisa GarcíaVázquez, Maria A. Iborra, and Manuel Segovia, Hospital Universitario Virgen de la Arrixaca, and Universidad de Murcia, Murcia, Spain, E-mails: elisagv@um.es, asunib@yahoo.com, and msegovia@um.es.

\section{REFERENCES}

1. Chagas C, 1909. Nova tripanozomiaze humana. Estudos sobre a morfolojia e o ciclo evolutivo do Schizotrypanum cruzin. gen., $\mathrm{n}$. sp., ajente etiolojico de nova entidade morbida do homem. Mem Inst Oswaldo Cruz 1: 159-218.

2. Soriano-Arandes A, Angheben A, Serre-Delcor N, Treviño-Maruri B, Gómez I, Prat J, Jackson Y, 2016. Control and management of congenital Chagas disease in Europe and other nonendemic countries: current policies and practices. Trop Med Int Health 21: 590-596.

3. Jannin J, Villa L, 2007. An overview of Chagas disease treatment. Mem Inst Oswaldo Cruz 102 (Suppl 1): 95-98.

4. WHO, 2002. Control of Chagas Disease: Second Report of the WHO Expert Committee. Available at: https://apps.who.int/ iris/bitstream/handle/10665/42443/WHO_TRS_905.pdf? sequence $=1$ \&isAllowed $=y$. Accessed November 20, 2019.

5. Alpern JD, Lopez-Velez R, Stauffer WM, 2017. Access to benznidazole for Chagas disease in the United States-cautious optimism? PLoS Negl Trop Dis 11: e0005794.

6. Murcia L, Simón M, Carrilero B, Roig M, Segovia M, 2017. Treatment of infected women of childbearing age prevents congenital Trypanosoma cruzi infection by eliminating the parasitemia detected by PCR. $J$ Infect Dis 215: 1452-1458.

7. CarlierY,Torrico F, Sosa-Estani S, Russomando G, Luquetti A, Freilij H, Albajar-Vinas $P, 2011$. Congenital Chagas disease: recommendations for diagnosis, treatment and control of newborns, siblings and pregnant women. PLoS Negl Trop Dis 5: e1250.
8. Vela-Bahena LE, Vergara R, Vite L, Ramos C, 2015. Postpartum treatment without interrupting breastfeeding in a patient with Chagas disease. Ginecol Obstet Mex 83: 487-493.

9. García-Bournissen F, Moroni S, Marson ME, Moscatelli G, Mastrantonio G, Bisio M, Cornou L, Ballering G, Altcheh J, 2015. Limited infant exposure to benznidazole through breast milk during maternal treatment for Chagas disease. Arch Dis Child 100: 90-94.

10. de Toranzo EG, Masana M, Castro JA, 1984. Administration of benznidazole, a chemotherapeutic agent against Chagas disease, to pregnant rats. Covalent binding of reactive metabolites to fetal and maternal proteins. Arch Int Pharmacodyn Ther 272: 17-23.

11. Cucunubá ZM et al., 2017. First Colombian consensus on congenital Chagas and clinical approach for women of childbearing age diagnosed with Chagas. Infect 21: 255-266.

12. Dias JC et al., 2016. 2nd Brazilian consensus on Chagas disease, 2015. Rev Soc Bras Med Trop 49 (Suppl 1): 3-60.

13. Almuna R, Salgado E, Reyes H, Gottlieb B, Capetillo M, 1981. Chagas disease and pregnancy. Review apropos of a clinical case treatment. Rev Chil Obstet Ginecol 46: 107-111.

14. Corrêa VR, Barbosa FG, Melo Junior CA, D'Alburquerque E, Castro LF, Andrade Junior HF, Nascimento N, 2014. Uneventful benznidazole treatment of acute Chagas disease during pregnancy: a case report. Rev Soc Bras Med Trop 47: 397-400.

15. Bisio M, Altcheh J, Lattner J, Moscatelli G, Fink V, Burgos JM, Bournissen FG, Schijman AG, Freilij H, 2013. Benznidazole treatment of Chagasic encephalitis in pregnant woman with AIDS. Emerg Infect Dis 19: 1490-1492.

16. Aldasoro E, Posada E, Requena-Méndez A, Calvo-Cano A, Serret N, Casellas A, Sanz S, Soy D, Pinazo MJ, Gascon J, 2018. What to expect and when: benznidazole toxicity in chronic Chagas' disease treatment. J Antimicrob Chemother 73: 1060-1067.

17. Murcia L, Carrilero B, Muñoz MJ, Iborra MA, Segovia M, 2010. Usefulness of PCR for monitoring benznidazole response in patients with chronic Chagas' disease: a prospective study in a non-diseaseendemic country. J Antimicrob Chemother 65: 1759-1764.

18. Abramowicz M, Zuccotti G, Pflomm JM, 2004. The Medical Letter on Drugs and Therapeutics. Drugs for Parasitic Infections. New Rochelle, NY: The Medical Letter.

19. Cancado JR, 2002. Long term evaluation of etiological treatment of Chagas disease with benznidazole. Rev Inst Med Trop Sao Paulo 44: 29-37.

20. Kuschnir E, Sgammini H, Castro R, Evequoz C, Ledesma R, Brunetto J, 1985. Evaluation of cardiac function by radioisotopic angiography, in patients with chronic Chagas cardiopathy. Arq Bras Cardiol 45: 249-256.

21. Howard EJ, Xiong X, Carlier Y, Sosa-Estani S, Buckens P, 2014. Frequency of the congenital transmission of Trypanosoma cruzi: a systematic review and meta-analysis. BJOG 121: 22-33.

22. Viotti R, Vigliano C, Lococo B, Bertocchi G, Petti M, Alvarez MG, Postan M, Armenti A, 2006. Long-term cardiac outcomes of treating chronic Chagas disease with benznidazole versus no treatment: a nonrandomized trial. Ann Intern Med 144: 724-734.

23. Viotti R, Vigliano C, Lococo B, Alvarez MG, Petti M, Bertocchi G, Armenti A, 2009. Side effects of benznidazole as treatment in chronic Chagas disease: fears and realities. Expert Rev Anti Infect Ther 7: 157-163.

24. Coura JR, de Abreu LL, Willcox HP, Petana W, 1997. Comparative controlled study on the use of benznidazole, nifurtimox and placebo, in the chronic form of Chagas' disease, in a field area with interrupted transmission. I. Preliminary evaluation. Rev Soc Bras Med Trop 30: 139-144.

25. Hasslocher-Moreno AM, do Brasil PE, de Sousa AS, Xavier SS, Chambela MC, Sperandio da Silva GM, 2012. Safety of benznidazole use in the treatment of chronic Chagas' disease. $J$ Antimicrob Chemother 67: 1261-1266.

26. Czeizel AE, Kazy Z, Vargha P, 2003. Oral tinidazole treatment during pregnancy and teratogenesis. Int J Gynaecol Obstet 83: 305-306.

27. Cantu JM, Garcia-Cruz D, 1982. Midline facial defect as a teratogenic effect of metronidazole. Birth Defects Orig Artic Ser 18: 85-88.

28. Giknis ML, Damjanov I, 1983. The transplacental effects of ethanol and metronidazole in Swiss Webster mice. Toxicol Lett 19: 37-42.

29. Roe FJ, 1985. Safety on nitroimidazoles. Scand J Infect Dis Suppl 46: $72-81$. 